\title{
The Association between Nuchal Cord Detection and Perinatal Outcomes in Term Infants: A Prospective Study
}

\author{
GAMAL A. IBRAHIM, M.D.*; MOSTAFA A. SAFWAT, M.Sc.*; SHERIF E. ABDELMONEM, M.D.** and \\ SHERINE H.M. GADALLA, M.D.*
}

The Departments of Obstetrics \& Gynecology* and Pediatrics**, Faculty of Medicine, Cairo University

\begin{abstract}
Background: Nuchal cord is a defined as a full twist of umbilical cord around fetal neck for at least one round. While most nuchal cords have no adverse clinical consequences, emerging reports have demonstrated significant associations between the presence of nuchal cord and maternal/fetal outcomes, which appears to be correlated with the tightness and number of cords around the neck.

Aim of Study: In this study, we investigated the association between nuchal cord detection during labor and perinatal outcome among full term pregnant women.

Material and Methods: We conducted a prospective study on 250 full term pregnant women, who were examined by two-dimensional US and color Doppler US to detect nuchal cord presence. Only women with cephalic presentation and sonographicaly detected nuchal cord were included. The study's outcomes included mode of delivery, APGAR scoring at 1 and $5 \mathrm{~min}$, need for admission in neonatal Intensive care unit (NICU), and blood gases of the newborn.

Results: The mean age of studied group was $26.86 \pm 5.53$ years and the mean parity was $1.59 \pm 1.21$. Overall, $83 \%$ of the women had one loop.

Conclusions: In conclusion, the presence of two or more nuchal loops may affect the mode of delivery and early neonatal outcome.
\end{abstract}

Key Words: Nuchal cord - Mode of delivery - Neonatal outcomes - Color doppler - Cord around fetal neck.

\section{Introduction}

DESPITE that the description of nuchal cord was recorded 400 years B.C, the study of clinical implications of this prevalent condition has increased only in the past few decades, particularly after the evolving number of studies linking it to poor perinatal outcomes [1]. Nuchal cord is a defined as a

Correspondence to: Dr. Gamal A. Ibrahim, The Department of Obstetrics \& Gynecology, Faculty of Medicine, Cairo University full twist of umbilical cord around fetal neck for at least one round [2]. The incidence of nuchal cord varies substantially amongst the published literature; however, observational studies reported an incidence rates ranging from 10 to $30 \%$ [3,4]. Risk factors for nuchal cord include advanced maternal age, multiparity, and male infants; nonetheless, the current body of evidence shows conflicting results regarding the significance of these risk factors [ 5,6]. Albeit the pathogenesis of nuchal cord is unclear, excessive fetal movements, dysregulated growth of the fetus or umbilical cords, vascular abnormalities, inadequate tensile strength and elastic forces, and poly or oligohydramnios are widely implicated in the pathogenesis of nuchal cord $[7,8]$. The diagnosis of nuchal cord is usually done by ultrasound (US) examination, through the detection of divot sign and abnormal flow velocimetry [2].

While most nuchal cords have no adverse clinical consequences, emerging reports have demonstrated significant associations between the presence of nuchal cord and maternal/fetal outcomes, which appears to be correlated with the tightness and number of cords around the neck [1]. Tight cord can compress the blood flow within the umbilical vein and lead to variable degrees of strangulation-like effects including hypoxia, anemia, and acidosis [9,10]. Physical, infants with nuchal cord may exhibit facial petechiae, conjunctival/ retinal hemorrhage, pallor, and hyoid bone fractures; these features may progressive in sever forms respiratory distress, hypotonia, and need for resuscitation [2,11]. This was confirmed by autopsy studies, which demonstrated significant hypoxia in stillbirths with nuchal cord [9]. Besides, nuchal cord was reported to significantly increase the risk of preterm labor and Caesarean delivery (CS) [12]. 
In this study, we investigated the association between nuchal cord detection during labor and perinatal outcome among full term pregnant women.

\section{Patients and Methods}

In this, cross sectional, prospective, study, we recruited pregnant women through the period from 2014 to 2017 at Kasr Al Ainy Maternity Hospital. Only women who agreed to sign the informed consent were included. An official approval of the responsible ethics committee was obtained before enrollment phase.

\section{Study participant and data collection:}

The present study included pregnant females, who were scheduled to underwent normal vaginal delivery at term (37-40 gestational weeks), during the study period. Women were included if they gad singleton fetus with cephalic presentation and documented nuchal cord by US. We excluded women with gestational hypertension or diabetes, preeclampsia, congenital abnormalities, amniotic fluid abnormalities, and/or history of previous cesarean section or scarred uterus.

All eligible women underwent full history taking and clinical examination. Besides, the routine laboratory parameters were obtained. Eligible women underwent two-dimension and color Doppler ultrasonography using an SSD-1700 ultrasound scanner (Aloka, Tokyo, Japan) equipped with a 3.5-MHz convex-array transducer.

The presence of nuchal cord was confirmed at time of delivery and number of loops around the neck were recorded.

Study's outcomes:

The primary outcome of the present study was the association between the presence and number of nuchal cords with neonatal outcomes (APGAR scoring at 1 and 5min, need for admission in neonatal Intensive care unit (NICU), and blood gases of the newborn). While the secondary outcome included the association between the presence and number of nuchal cords with mode of delivery.

\section{Statistical analysis:}

Data were analyzed using Statistical Program for Social Science (SPSS) version 20.0. We employed descriptive analysis [mean \pm standard deviation (SD) and frequency for quantitative and qualitative data, respectively] to describe different parameters of the study. The association between the presence and number of nuchal cords with study outcomes was examined using Chi-square test.

\section{Results}

The mean age of studied group was $26.86 \pm 5.53$ years and the majority of the women were para 1 and 2. The mean gestational age was $38.24 \pm 1.218$ weeks and the estimated fetal weight was $3.236 \pm$ $0.378 \mathrm{Kg}$. Nearly $42 \%$ of the fetuses were males ( Table 1).

Table (1): Baseline characteristics of the included women.

\begin{tabular}{|c|c|c|}
\hline & Frequency $(n=250)$ & Percentage \\
\hline \multicolumn{3}{|l|}{$\overline{\text { Age: }}$} \\
\hline Mean \pm SD & \multicolumn{2}{|c|}{$26.86 \pm 5.536$} \\
\hline \multicolumn{3}{|l|}{ Parity: } \\
\hline Nulli-para & 50 & 20.0 \\
\hline Para 1 & 78 & 31.2 \\
\hline Para 2 & 69 & 27.6 \\
\hline Para 3 & 35 & 14.0 \\
\hline Para 4 & 14 & 5.6 \\
\hline Para 5 & 4 & 1.6 \\
\hline \multicolumn{3}{|l|}{ GA: } \\
\hline Mean \pm SD & \multicolumn{2}{|c|}{$38.24 \pm 1.218$} \\
\hline \multicolumn{3}{|l|}{$E F W$ : } \\
\hline Mean \pm SD & \multicolumn{2}{|c|}{$3.236 \pm 0.3789$} \\
\hline \multicolumn{3}{|l|}{ MOD: } \\
\hline CS & 21 & 8.4 \\
\hline Vaginal & 229 & 91.6 \\
\hline \multicolumn{3}{|l|}{ Reason for CS: } \\
\hline Failed progress & 13 & 62.0 \\
\hline Fetal distress & 8 & 38.0 \\
\hline \multicolumn{3}{|l|}{ Neonatal gender: } \\
\hline Female & 143 & 57.2 \\
\hline Male & 107 & 42.8 \\
\hline
\end{tabular}

Ninety women had loop around the cord by 2D US; while all women had loop around the cord by color Doppler. During labor, only 235 women ( 94\%) had loops around the neck after delivery. More than one loop was detected in $16.8 \%$ of the women. Concerning perinatal outcomes, $4.4 \%$ of the fetus had meconium staining and $12.4 \%$ had CTG changes during delivery. The 1 and 5-minutes APGAR scores were below 7 in $5.2 \%$ and $2 \%$ of the fetuses, respectively. Two percent of the fetuses need NICU admission. Concerning the mode of delivery, $8.4 \%$ of the women had CS (Table 2).

The association analysis demonstrated that there is significant association between number of loops of cord around the neck and mode of delivery $(p<0.001)$, with higher incidence of CS rates in women with two and three loops. In addition, there was highly significant association nrecence of three 
loops of cord around the neck and meconium staining $(p<0.001)$. There was no evidence of CTG changes in patients having no loops of cord around the neck; on the other hand, $4.3 \%$ and $76.2 \%$ of patients having one and two loops of cord around the neck developed CTG changes, respectively. All patients having three loops of cord around the neck developed CTG changes. There was significant association between number of loops of cord around the neck and CTG changes during labor $(p$ $<0.001)$. Besides, $28.6 \%(\mathrm{n}=6)$ of patients having two loops of cord around the neck having APGAR score $<7$, and $83.3 \%(n=5)$ of patients having three loops of cord around the neck having APGAR score $<7$. There was significant association between number of loops of cord around the neck and 1 min APGAR score as evident by $(p<0.001)$. Likewise, $50 \%(n=3)$ of patients having three loops of cord around the neck had APGAR score <7. There was significant association between number of loops of cord around the neck and 5 min APGAR score $(p<0.001)$. Finally, $9.5 \%(\mathrm{n}=2)$ of patients having two loops of cord around the neck had NICU admission and $50 \%(\mathrm{n}=3)$ of patients having three loops of cord around the neck admitted in the NICU. There was significant association between number of cords around the neck and NICU admission as evident by $p$-value $<0.001$ (Table 3 ).

Table (2): Frequency of detecting loops of cord around the neck, perinatal outcomes, and mode of delivery.

\begin{tabular}{|c|c|c|}
\hline & $\begin{array}{l}\text { Frequency } \\
(\mathrm{n}=250)\end{array}$ & Percentage \\
\hline \multicolumn{3}{|c|}{ Loops of cord around the neck detected by $2 \mathrm{D} U / S$ : } \\
\hline Not detected & 90 & 36.0 \\
\hline Detected & 160 & 64.0 \\
\hline \multicolumn{3}{|c|}{ Loops of cord around the neck detected by color Doppler: } \\
\hline Detected & 250 & 100.0 \\
\hline \multicolumn{3}{|c|}{ Loops of cord around the neck detected after delivery: } \\
\hline Not detected & 15 & 6.0 \\
\hline Detected & 235 & 94.0 \\
\hline \multicolumn{3}{|c|}{ Number of loops around the neck detected after delivery: } \\
\hline No loops & 15 & 6.0 \\
\hline 1 loop & 208 & 83.2 \\
\hline 2 loops & 21 & 8.4 \\
\hline 3 loops & 6 & 2.4 \\
\hline \multicolumn{3}{|c|}{ Meconium staining during delivery: } \\
\hline No meconium & 239 & 95.6 \\
\hline Meconium & 11 & 4.4 \\
\hline \multicolumn{3}{|c|}{ CTG changes during delivery: } \\
\hline No & 219 & 87.6 \\
\hline Yes & 31 & 12.4 \\
\hline \multicolumn{3}{|l|}{1 min APGAR score: } \\
\hline$<7$ & 13 & 5.2 \\
\hline$>7$ & 237 & 94.8 \\
\hline \multicolumn{3}{|l|}{ 5min APGAR score: } \\
\hline$<7$ & 5 & 2.0 \\
\hline$>7$ & 245 & 98.0 \\
\hline \multicolumn{3}{|l|}{ Neonatal ABG: } \\
\hline$<7.2$ & 11 & 4.4 \\
\hline$>7.2$ & 239 & 95.6 \\
\hline \multicolumn{3}{|l|}{ NICU admission: } \\
\hline No & 245 & 98.0 \\
\hline Yes & 5 & 2.0 \\
\hline \multicolumn{3}{|l|}{ MOD: } \\
\hline CS & 21 & 8.4 \\
\hline Vaginal & 229 & 91.6 \\
\hline \multicolumn{3}{|l|}{ Reason for CS: } \\
\hline Failed progress & 13 & 62.0 \\
\hline Fetal distress & 8 & 38.0 \\
\hline
\end{tabular}


Table (3): The results of association analyses.

\begin{tabular}{|c|c|c|c|c|c|c|c|c|c|c|c|c|}
\hline \multirow{3}{*}{ Variables } & \multicolumn{8}{|c|}{ Number of loops after delivery } & \multirow{2}{*}{\multicolumn{2}{|c|}{ Total }} & \multirow{3}{*}{$\begin{array}{l}\text { Chi- } \\
\text { Square }\end{array}$} & \multirow{3}{*}{$\begin{array}{c}p- \\
\text { value }\end{array}$} \\
\hline & \multicolumn{2}{|c|}{0} & \multicolumn{2}{|c|}{1} & \multicolumn{2}{|c|}{2} & \multicolumn{2}{|c|}{3} & & & & \\
\hline & $\mathrm{N}$ & $\%$ & $\mathrm{~N}$ & $\%$ & $\mathrm{~N}$ & $\%$ & $\mathrm{~N}$ & $\%$ & $\mathrm{~N}$ & $\%$ & & \\
\hline \multicolumn{13}{|l|}{$\overline{M O D:}$} \\
\hline CS & 2 & 13.3 & 5 & 2.4 & 9 & 42.9 & 5 & 83.3 & 21 & 8.4 & 86.383(a) & 0.000 \\
\hline VD & 13 & 86.7 & 203 & 97.6 & 12 & 57.1 & 1 & 16.7 & 229 & 91.6 & & \\
\hline Total & 15 & 100 & 208 & 100 & 21 & 100 & 6 & 100 & 250 & 100 & & \\
\hline \multicolumn{13}{|c|}{ Meconium staining: } \\
\hline No & 15 & 100 & 206 & 99 & 17 & 81 & 1 & 16.7 & 239 & 95.6 & 106.119(a) & 0.000 \\
\hline Yes & 0 & 0 & 2 & 1 & 4 & 19 & 5 & 83.3 & 11 & 4.4 & & \\
\hline Total & 15 & 100 & 208 & 100 & 21 & 100 & 6 & 100 & 250 & 100 & & \\
\hline \multicolumn{13}{|c|}{ CTG changes: } \\
\hline No & 15 & 100 & 199 & 95.7 & 214 & 96 & No & 15 & 100 & 199 & $.676(b)$ & 0.000 \\
\hline Yes & 0 & 0 & 9 & 4.3 & 9 & 4 & Yes & 0 & 0 & 9 & & \\
\hline Total & 15 & 100 & 208 & 100 & 223 & 100 & Total & 15 & 100 & 208 & & \\
\hline \multicolumn{13}{|c|}{$A P G A R-1:$} \\
\hline$<7$ & 0 & 0 & 2 & 1 & 2 & 0.9 & $<7$ & 0 & 0 & 2 & $.146(b)$ & 0.000 \\
\hline$>7$ & 15 & 100 & 206 & 99 & 221 & 99.1 & $>7$ & 15 & 100 & 206 & & \\
\hline Total & 15 & 100 & 208 & 100 & 223 & 100 & Total & 15 & 100 & 208 & & \\
\hline \multicolumn{13}{|c|}{ APGAR-5: } \\
\hline$<7$ & 0 & 0 & 0 & 0 & 2 & 9.5 & 3 & 50 & 5 & 2 & 81.147(a) & 0.000 \\
\hline$>7$ & 15 & 100 & 208 & 100 & 19 & 90.5 & 3 & 50 & 245 & 98 & & \\
\hline Total & 15 & 100 & 208 & 100 & 21 & 100 & 6 & 100 & 250 & 100 & & \\
\hline \multicolumn{13}{|l|}{$N I C U$ : } \\
\hline No & 15 & 100 & 208 & 100 & 19 & 90.5 & 3 & 50 & 245 & 98 & 81.147(a) & 0.000 \\
\hline Yes & 0 & 0 & 0 & 0 & 2 & 9.5 & 3 & 50 & 5 & 2 & & \\
\hline Total & 15 & 100 & 208 & 100 & 21 & 100 & 6 & 100 & 250 & 100 & & \\
\hline
\end{tabular}

\section{Discussion}

A growing body of evidence has linked nuchal cord to poor perinatal outcomes. In the present study, we demonstrated that not only the presence or absence of cord influences the mode of delivery or perinatal outcome, but also the main factor is the number of coils around the neck. Mode of delivery and perinatal outcomes were not significantly influenced by the presence of one loop of cord around the neck but, on the other side, were significantly influenced by the presence of two or more loops of cord around the neck.

The incidence of the nuchal cord was $18.8 \%$, and the single loop was the most common finding in our study, which is nearly similar to the incidence reported by Singh et al. [13], (18.57\%) and Joshi et al. [14], (19.76\%). Among the 235 newborns in the study group with nuchal cords, $208(88.5 \%)$ had one loop, $21(8.9 \%)$ had two loops, and 6 ( $2.6 \%$ ) had three loops. Similarly, Shrestha et al. [ 15], in their study found that single nuchal cord loops were more prevalent than multiple nuchal cord loops. In our study, the incidence of nuchal cord loop was more in multigravida $(80 \%)$ in comparison to primigravida (20\%). Likewise, Onderoglu et al. [16], quoted that the incidence of nuchal cord loop in the case of multigravida was higher $(65.1 \%)$ compared to primigravida (34.9\%). On the other hand, Tamrakar et al. [17], quoted that the incidence of nuchal cord loop in the case of primigravida was higher $(62.98 \%)$, But no obvious reason was stated for this.

According to the study of Ghi et al. [18], the nuchal cord was detected in $32 \%$ of neonates. The chance of vaginal delivery within 24 hours from labor induction was comparable among the neonates with and without nuchal cord at birth $(53 \%$ versus $59 \%$ ), respectively. Consequently, the risk of induction failure does not seem to be increased with the entangled cord around the fetal neck, which came along with our study; the rate of CS was not significantly increased with the presence of one loop of cord around the neck (2.4\%). However, in our study, the rate of CS increased significantly in case of the presence of two (42.9\%) or three ( $83.3 \%$ ) loops of cords around the neck. 
Shrestha et al. [15], reported a $23 \%$ incidence rate of nuchal cord. In addition, they highlighted that in the nuchal cord group, the APGAR score $<7$ at 1 minute was substantially low $(p=0.010)$, and the APGAR score at 5 minutes was not frequent. In the nuchal cord group, intrapartum complications such as FHR abnormalities and meconium staining of liquor were increased but not statistically significant. Therefore, nuchal cord is not associated with adverse perinatal outcome, and that correlates with the findings of our study in the presence of just one loop, but in our study, in the presence of several loops, the perinatal outcome was studied separately and poor perinatal outcomes were observed in the presence of two or more loops around the neck.

During the third trimester sonography, sonographic detection of the nuchal cord may be a significant finding, in particular when assessing cases of deteriorating fetal movements [19]. This agrees with the results of our study despite the fact that there was no perinatal mortality; however, results were significant only in case of presence of two or more loops of cord around the neck and not statistically significant in case of presence of only one loop of cord around the neck regarding meconium staining, CTG changes, 1-5min APGAR score, neonatal ABG and the need for NICU admission. In the view of our data, the presence of a single loop of nuchal cord has no Impact on the perinatal outcome, including the cord blood gases. On the other side, the presence of two or three loops had a negative impact on all perinatal outcomes, including (meconium staining, CTG changes, 1-5min APGAR score, neonatal ABG, and the need for NICU admission).

\section{Conclusion:}

In conclusion, the presence of two or more nuchal loops may affect the mode of delivery and early neonatal outcome. Once nuchal cord is highly suspected either antenatal or intrapartum, patients should be closely monitored or shifted to a special ward offering close monitoring to fetal heart rate, CTG changes and progress of labor. If two or more loops of cord around the neck is highly suspected, patients should be counseled for all the possible risks and complications they may encounter during delivery or after labor.

\section{References}

1- CLAPP J.F., STEPANCHAK W., HASHIMOTO K., EHRENBERG $\mathrm{H}$. and LOPEZ B.: The natural history of antenatal nuchal cords. Am. J. Obstet. Gynecol., 189 (2): 488-493, 2003.

2- PEESAY M.: Nuchal cord and its implications. Matern Heal Neonatol. Perinatol., 3 (1): 28, 2017.
3- HENRY E., ANDRES R.L. and CHRISTENSEN R.D.: Neonatal outcomes following a tight nuchal cord. J. Perinatol., 33 (3): 231-234, 2013.

4- LARSON J.D., RAYBURN W.F., CROSBY S. and THURNAU G.R.: Multiple nuchal cord entanglements and intrapartum complications. Am. J. Obstet. Gynecol., doi: 10. 1016/0002-9378(95)91359-9, 1995.

5- MISER W.F.: Outcome of infants born with nuchal cords. Obstet. Gynecol. Surv., 47 (11): 767-769, 1992.

6- HENRY E., ANDRES R.L. and CHRISTENSEN R.D.: Neonatal outcomes following a tight nuchal cord. J. Perinatol., 33 (3): 231-234, 2013.

7- LACRO R.V., JONES K.L. and BENIRSCHKE K.: The umbilical cord twist: Origin direction, and relevance. Am. J Obstet Gynecol., doi: 10.1016/S0002-9378(87) 80067- 4, 1987.

8- HORN L.C., FABER R., STEPAN H., SIMONE., ROBEL R. and WITTEKIND C.: Umbilical cord hypercoiling and thinning: A rare cause of intrauterine death in the second trimester of pregnancy. Pediatr. Dev. Pathol., doi: 10.2350/08-05-0095.1, 2006.

9- BAERGEN R.N.: Cord abnormalities, structural lesions, and cord 'accidents'. Semin Diagn. Pathol., doi: 10. 1053/j.semdp.2007.02.004, 2007.

10- SHEPHERD A.J., RICHARDSON C.J. and BROWN J.P.: Nuchal Cord as a Cause of Neonatal Anemia. Am. J. Dis. Child., 139 (1): 71-73, 1985.

11- PEESAY M.: Cord around the neck syndrome. BMC Pregnancy and Childbirth, doi:10.1186/1471-2393-12S1-A6, 2012.

12-STRONG T.H., JARLES D.L., VEGA J.S. and FELDMAN D. B.: The umbilical coiling index. Am. J. Obstet. Gynecol., 170 (1): 29-32, 1994.

13- SINGH G. and SIDHU K.: Nuchal Cord: A retrospective analysis. Med J Armed Forces India, doi: 10.1016/S03771237(08)80102-5, 2008.

14- JOSHI K., SAXENA R., BHAT M., LOMROD Y. and VERMA K.: Incidence of cord around the neck and its effects on labour and neonatal outcome. Adv. Hum. Biol., doi: 10.4103/2321-8568.199535, 2017.

15- SHRESTHA N.S. and SINGH N.: Nuchal cord and perinatal outcome. Kathmandu Univ. Med. J., doi: 10.1097/ 00006250-200304001-00171, 2007.

16- ÖNDEROGLU L.S., DURSUN P. and DURUKAN T.: Perinatal features and umbilical cord blood gases in newborns complicated with nuchal cord. Turk J. Pediatr. 2008.

17- TAMRAKAR S.R.: Incidence of nuchal cord, mode of delivery and perinatal outcome: A notable experience in Dhulikhel Hospital - Kathmandu University Hospital. Nepal Med. Coll. J., 2013.

18- GHI T., D'EMIDIO L., MORANDI R., CASADIO P., PILU G. and PELUSI G.: Nuchal cord entanglement and outcome of labour induction. J. Prenat Med., 2007.

19- JAUNIAUX E., RAMSAY B., PEELLAERTS C. and SCHOLLER Y.: Perinatal Features of Pregnancies Complicated by Nuchal Cord. Am. J. Perinatol., doi: 10. 1055/s2007-994467, 1995. 


\section{الحبل السرى القفوى المكتشف قرب تمام وفمدرة فترة الحمل

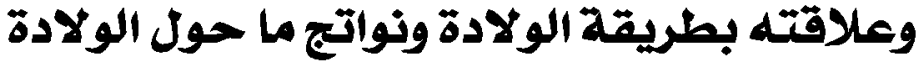

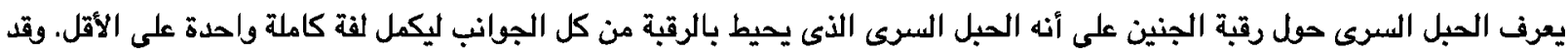

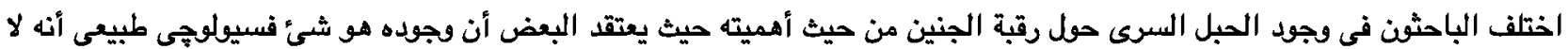
يتسبب فى إحداث مشاكل قبل أو أثناء الولادة.

ولكن البعض يعلل أسباب الأضرار التى يتعرض لها الطفل فود ولادته إلى وجود الحبل السرى حل رقبة الجنين بطريقة خانقة والتى قد تتسبب فى وفاة الطفل فول ولادته أو حتى داخل بطن الأمئ

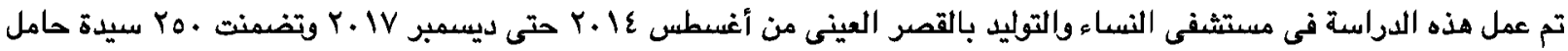

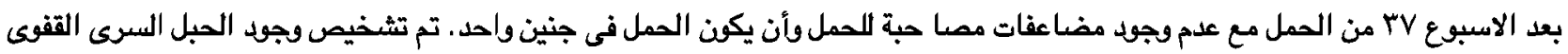
فى • مالة حالة عن طريق الموجات الصوتية ثنائية الأبعاد والدوبلر الملون.

وقد تم ملاحظة وجود علاقة مؤثرة بين وجود الحبل السرى القفوى وطريقة الولادة عند وجود أكثر من حلقة واحدة حطل رقبة الجنين. تم

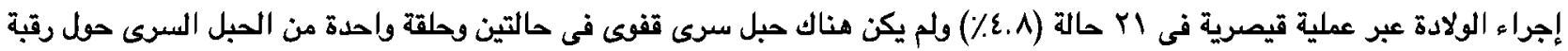

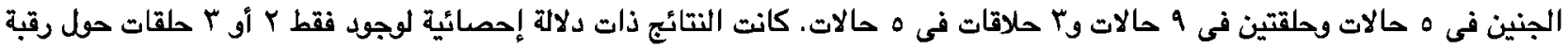
الجنين وليس لوجيد حلقة واحدة حل رقبة الجنين.

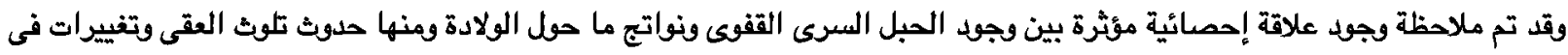
جهاز تخطيط نبض وحركة الجنين أثناء الولادة وحرز أبغاز أقل من V فى الدقيقة الأولى والخامسة وكل ذللك فقط عند وجود أكثر من حلقة واحدة حول رقبة الجنين.

ويالتالى فإن إمكانية التنبئ لوجود حلاثات من الحبل السرى حل رقبة الجنين قبل الولادة سوف تساعد الطبيب فى اتخاذ القرارات المناسبة ل الضمان سلامة الأم والطفل. 